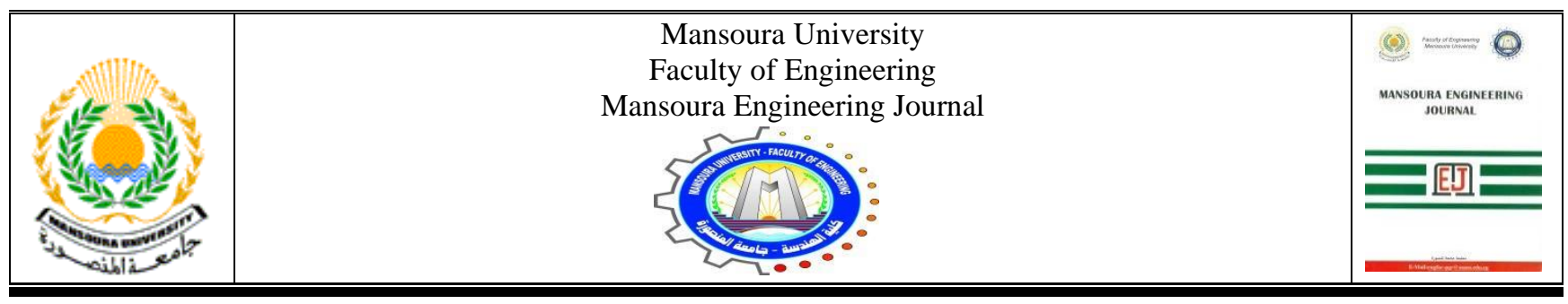

\title{
Optimal Location of EV-PV Charging Stations in a Radial Distribution System
}

\author{
El Shaimaa Mohamed Eid, Mohammed Saeed and Magdi El-Saadawi
}

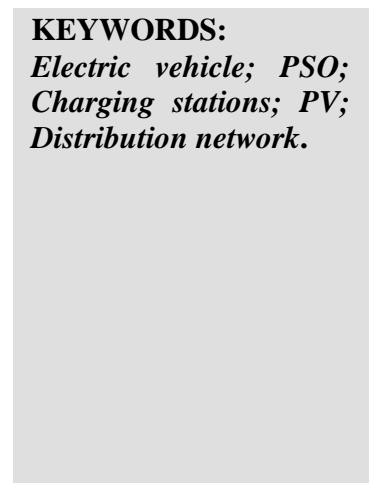

\begin{abstract}
The increasing penetration of electric vehicles (EVs) will greatly affect the operation of distribution networks. On one hand, the EVs can benefit the electric distribution systems. On the other hand, the connection of EVs to the distribution networks poses a series of new challenges for electric utility operators. This paper proposes an algorithm for optimal location of a combined EV-PV charging station in a distribution network for minimizing the system losses. The proposed method depends on PSO for solving the optimization problem. The method is performed in Matlab/Simulink and is applied to a 33bus radial distribution test system with and without integrating the PV system and the results are analyzed and compared. The obtained results show that the EV-PV charging station is a suitable solution for reducing the feeder losses rather than the charging stations without $P V$.
\end{abstract}

\section{INTRODUCTION}

$\mathrm{E}$ $\mathrm{V}$ is commonly referred to as an electric vehicle that utilizes one or more engines to propel it. EV can be considered as a moving battery. The EVs are categorized into many categories including electric cars, lorry/bus, trains, motorcycles, scooters, etc. EVs can also be classified into battery electric vehicles (BEV), plug-in hybrid electric vehicles (PHEV), and hybrid electric vehicles (HEV). From the charging point of view, the major difference between the three types is that PHEV/BEV provides an external charging option, while the HEV does not. The HEVs charge their batteries by the kinetics of their combustion engines [1]. Since the battery revolution has been started in the last few years, many types of higher efficiency, longer life, and higher energy density batteries were available. They are being developed day after day and this will have a great effect on increasing the performances of EVs and decreasing their costs. These types include Nickel-cadmium, Nickel-metal hydride, and Lithiumion batteries [2].

Received: (30 April, 2020) - revised: (15 October, 2020) - accepted: (30 November, 2020)

Corresponding Author: Shymaa Eid, Dept. of Electrical Engineering, Faculty of Engineering, Mansoura University
In recent years, proper operation of distribution systems integrated with EVs and renewable energy sources represents a great challenge for distribution system operators. From the electric grid point of view, EVs offer a lot of advantages including reduction of oil dependence and reduction of $\mathrm{CO}_{2}$ emissions, and they can be used for improving the performances of distribution systems. However, with increasing the penetration levels of the EVs integrated with electric utilities, an intelligent management system will be essential to avoid negative impacts of EVs on electric distribution systems. These impacts include the increase of electrical losses, lines capacity, voltage deviations, ... etc. [3]. The strategy of EVs charging can be useful for overall peak shaving and load leveling of the utility. In peak periods they can be used as a power source (V2G) and at low-load periods they can be recharged from the grid $(\mathrm{G} 2 \mathrm{~V})$. In general, charging the electric vehicles will impact the electric power system in two ways. First, the additional demand for recharging PEV batteries will impact the overall power demand and add complexity to managing electric power generation, transmission and distribution. The high charging loads of the fast charging

Assis. Prof. Mohammed Saeed, Dept. of Electrical Engineering, Faculty of Engineering, Mansoura University

Prof. Magdi El-Saadawi, Dept. of Electrical Engineering, Faculty of Engineering, Mansoura University 
stations results in increased peak load demand, reduced reserve margins, voltage instability, and reliability problems. Second, EVs can be seen both as a distributed storage technology or as flexible loads acting like a virtual power plant. Coordinated EV charging and vehicle to-grid (V2G) applications hold promise in integrated smart grids as opportunities to facilitate the integration of non-dispatchable renewable energy sources and, in general, improve the operation and reliability of the electric power system. As such, modelling of the impacts of PEV charging behavior is required to anticipate future needs [4-6].

One feasible solution to reduce the undesirable effects of EVs is to promote charging using other energy sources such as renewable energy. With the continuous decrease in the price of PV modules, solar energy can be considered as a competitive source for this purpose [7-8]. The application of PV power systems is greatly increased by the developments in installation practices, conversion and tracking technologies, and battery manufacturing technology [9]. One of the most convenient solutions for charging EVs at workplaces and parking areas can be obtained by roofing the carpark with PV modules. Such an arrangement creates the opportunity for "charging while parking" [10].

In the literature, many researchers have investigated the design and operation of EV-PV-CSs on the distribution systems. The authors in [11] proposed a new concept and an operation algorithm of bi-directional battery charger for plug-in hybrids vehicles PHEV with a PV power system. The battery charger system was designed to have the function of PV power conversion and battery charging and discharging. In [12] the authors presented a system to partially mitigate the distribution feeder overloading by providing fast charging for the EV battery from the PV system. A bidirectional dc-dc EV charger was placed between the high-voltage dc bus of a PV inverter and the EV battery. A proposed solar carport architecture was introduced in [13]. The proposed system created a seamless power flow by providing a three-port interface to PHEVs, PV panels, and the utility grid and hence improved the performance over existing battery charging schemes.

Different architectures of EV-PV chargers were examined and analyzed in [14]. In that study, two optimal designs for the EV-PV charger were introduced. The authors in [15] introduced a design of a smart charging station in which the charging of the PHEVs was controlled to mitigate the effect of charging during peak load period isn't felt on the grid. In that system, the PHEVs were charged through the grid-connected PV system and/or the utility. A special controller was designed to enable effective transfer of energy while decreasing the conversion phases between source and load [16]. The system is composed of modules to enhance flexibility and facilitate development. The integration of a PV system and EVs under an uncontrolled charging regime was studied in [17]. The application of smart charging and V2G strategies were also investigated. The paper proved that the vehicle to grid strategy could be used for utilizing the PV output in shaving the peaks of the conventional load curve.

In [18], the authors proposed an optimal design of Electric Vehicle Charging Station (EVCS) considering renewable energy and diesel generation. The objective of the optimization was to minimize the lifecycle cost while considering environmental emissions. The authors in [19] investigated the possibility of charging EV at the workplace using a PV power system with optimal storage size. To minimize the grid dependency and to maximize the usage of PV energy to directly charge the EV, different dynamic EV charging profiles were examined and a comparison between these profiles was introduced. Authors in [20] presented a proposed fast EVCS model connected to the distribution network. The proposed model increased power quality by reducing harmonic currents. An energy management strategy based on optimal power flow was also presented by connecting a PV power system with EVCS to decrease the impact of fast charging on the grid. In [21] a genetic algorithm was used to optimize the installation and operation of EV fast-charging by maximizing the profit measured by its net present value. Wind, PV, and storage systems were connected to EVCS in order to enhance the profitability of the stations and to decrease the high energy demanded from the grid.

This paper discusses the impact of EV-PV-CSs on electric feeder losses. The main objective of the paper is to detect the optimal allocation of CSs for loss reduction subjected to system constraints. The PSO technique is used to determine the optimal placement for the CSs. The proposed algorithm is applied to a standard 33-bus radial distribution system with integrated PV at different conditions and without integrating the PV system and the results are analyzed and compared.

The rest of this paper is organized as follows; section two presents the mathematical formulation of the problem. The definitions and description of the PSO method are introduced in section three. Section four presents the procedure used for solving the problem whereas section five introduces numerical applications and case studies. The results and discussions are introduced in section six, whereas section seven concludes the paper.

\section{PROBLEM FORMULATION}

The problem is formulated as an optimization problem for general CSs placement considering practical features of CS, the operational, and load restrictions at different load levels. The optimization problem is formulated with an objective function that is not differentiable. This paper proposes a solution algorithm depends on the PSO technique and aims to determine the locations where CSs are to be installed, and the sizes of PV to be installed. The algorithm can calculate the global optimal solution for siting the CSs.

\section{A. Objective function}

The main objective of this study is to estimate the best locations of CSs which decrease the system losses. The optimization problem is formulated as a single objective function. The PV power sources are assumed as negative load. The power output from the installed EV-PV through the day can be obtained from (1) - (4). [20] 


$$
\begin{gathered}
P_{P V}=\eta A_{P V} G\left(1-\frac{T_{C}-25}{200}\right) \\
I_{P V}=I_{p h}-I_{s a t} \exp \left(\frac{q\left(V_{p v}+I_{p v} * R_{s}\right)}{N K T_{p v}}\right) \\
-\frac{V_{p v}+I_{p v} * R_{s}}{R_{p}} \\
I_{p h}=I_{p h o}\left(1+K_{0}(T-300)\right) \\
I_{s a t}=K_{1} T^{3} e^{-\left(\frac{q V_{g}}{K T}\right)}
\end{gathered}
$$

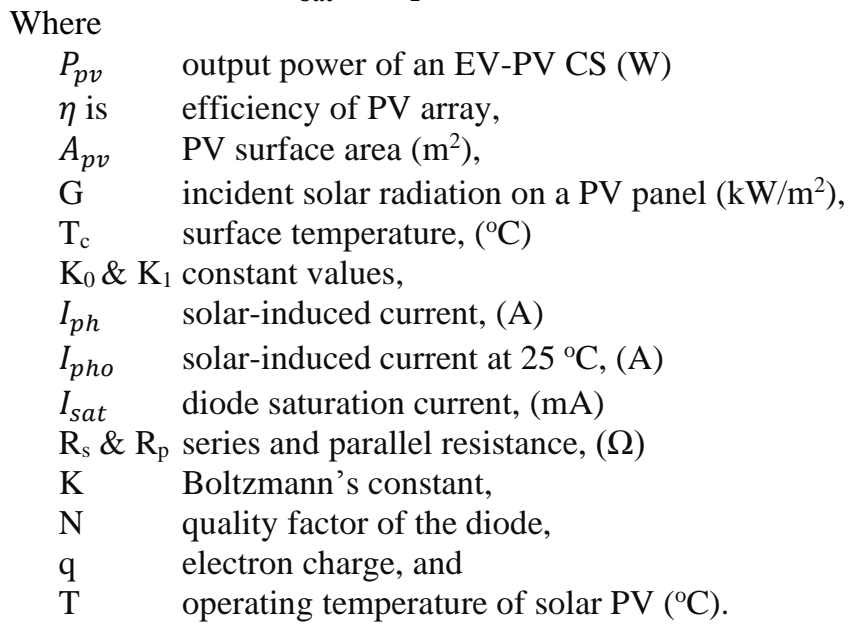

The calculation of the power loss in the line section connecting buses $\mathrm{i}$ and $\mathrm{j}$ before integrating any charging station can be formulated as [22]:

$$
P_{\text {Loss }}(i . j)=R_{i}\left(\frac{P_{i}^{2}+Q_{i}^{2}}{\left|V_{i}^{2}\right|}\right)
$$

Where

$\mathrm{R}_{\mathrm{i}} \quad$ the section line resistance, $\Omega$

$\mathrm{P}_{\mathrm{i}} \quad$ active power of the $\mathrm{i}^{\text {th }}$ bus, $\mathrm{W}$

$\mathrm{Q}_{\mathrm{i}} \quad$ reactive power of the $\mathrm{i}^{\text {th }}$ bus, VAr

$\mathrm{V}_{\mathrm{i}} \quad$ voltage of the $\mathrm{i}^{\text {th }}$ bus, $\mathrm{V}$

The total network losses are calculated as:

$$
P_{\text {TLoss }}(i . j)=\sum_{i=1}^{n} I_{i}^{2} R_{i}
$$

Where $\mathrm{n}$ is the total number of the system's line sections.

The network losses due to the added CSs can be formulated as [22]:

$$
P_{\text {TLoss }}^{\prime}=\sum_{i=1}^{n} I_{T}^{2} R_{i}
$$

where $I_{T}$ is the total line section current including the charging station current.

The losses with PV connection to the charging station are expressed as:

$$
P_{\text {TLoss }}^{\prime \prime}=\sum_{i=1}^{n}\left(I_{C S}-I_{p v}\right)^{2} R_{i}
$$

where $I_{p v}$ is the current delivered by the PV to the CS or the utility.

Substituting at (6) the proposed objective function can be expressed as:

$$
\text { Min. } P_{\text {Tloss }}=\sum_{i=1}^{n}\left(I_{i}+I_{c s}-I_{p v}\right)^{2} R_{i}
$$

\section{B. Constraints}

The research of power flow is a significant way of planning any future development of energy systems or for determining a current system's best function. The basic information obtained from the power flow studies is the magnitude of voltage, phase angle at each bus, and the power flowing in each line. These values are the essential values required to solve the specified optimization problem. To fulfill user preferences and technical limits, the predefined objective function is subject to a set of distinct constraints. These constraints include:

- Voltage constraints: maximum and minimum voltages limits at each busbar.

$$
V_{\min } \leq V_{i} \leq V_{\max }
$$

- Line loading constraints: maximum apparent power limit of each line.

$$
S_{i j} \leq S_{i j \_ \text {max }}
$$

- Charging stations' capacity constraints: maximum and minimum limits of each PV-CS capacity.

$$
C C S_{k_{-} \min } \leq C C S_{k} \leq C C S_{k_{-} \max }
$$

- Active power balance constraints: the total generated active power must equal the demand active power plus the losses.

$$
P_{j}=P_{i}-P_{\text {loss } . i}-P_{L j}
$$

- Reactive power balance constraints: the total generated reactive power must equal the demand active power plus

$$
\begin{aligned}
P_{j}=P_{i}-P_{\text {loss } . i}- & P_{L j} \\
& =P_{i}-\frac{R_{i}}{\left|V_{i}^{2}\right|}\left(P_{i}^{2}+\left(Q_{i}+Y_{i}\left|V_{i}^{2}\right|^{2}\right)^{2}\right)-P_{L . j}
\end{aligned}
$$

the losses.

$$
Q_{j}=Q_{i}-Q_{\text {loss.i }}-Q_{L \mathrm{j}}
$$

The last two equations can be modeled through the following mathematical relations [22]:

$$
\begin{aligned}
& Q_{j}=Q_{i}-Q_{\text {loss.i }}-Q_{L . j} \\
& =Q_{i} \\
& -\frac{X_{i}}{\left|V_{i}^{2}\right|}\left(P_{i}^{2}+\left(Q_{i}+Y_{i 1}\left|V_{i}^{2}\right|^{2}\right)^{2}\right) \\
& -Y_{i 1}\left|V_{i}^{2}\right|-Y_{i 2}\left|V_{j}^{2}\right|-Q_{L j} \\
& \left|V_{j}^{2}\right|=\left|V_{i}^{2}\right|+\frac{R_{i}^{2}+X_{i}^{2}}{\left|V_{i}\right|^{2}}\left(P_{i}^{2}+Q_{i}^{2}\right)-2\left(R_{i} P_{i}+X_{i} Q_{i}\right)
\end{aligned}
$$


Where,

$V_{\min } \cdot V_{\max }$ minimum and maximum bus voltages,

$C C S_{k} \quad$ capacity of the $k^{\text {th }} \mathrm{PV}$ charging station,

$C C S_{k \_ \text {min }}$ minimum capacity of the $k^{\text {th }}$ PV charging, station,

$C C S_{k_{-} \text {max }}$ maximum capacity of the $k^{\text {th }} \mathrm{PV}$ charging station,

$S_{i j} \quad$ apparent power in the line connecting between bus $i$ and bus $j$,

$S_{i j \_ \text {min }} \quad$ minimum apparent power of the line $i j$,

$S_{i j \_ \text {max }} \quad$ maximum apparent power of the line $i j$,

$P_{i}, Q_{i} \quad$ real and reactive power flow out of the $i^{t h}$ bus,

$P_{L j}, Q_{L j} \quad$ load real and reactive power at busj,

$R_{i}, X_{i} \quad$ section line resistance and reactance respectively.

\section{PARTICLE SWARM OPTIMIZATION TECHNIQUE}

The abovementioned optimization problem will be solved based on the PSO technique to obtain the optimum location of EV-CSs which minimize the network losses and improve the voltage profile. The PSO algorithm has many advantages, including easy implementation and fast convergence. Compared to other artificial intelligence methods, the computational time is less [23]. These advantages make it a suitable algorithm for solving the studied optimization problem.

The PSO technique is a swarm intelligence algorithm that is widely used in optimization problems. Many PSO algorithms were successfully applied to solving different power engineering problems [24]. These applications include issues with engineering design, structural optimization, distribution, and location. PSO technique is motivated by bird flocking's social behavior and was introduced first by Kennedy and Eberhart [24]. The method of optimization in the PSO algorithm begins with a randomly generated population made up of so-called particles. Each particle has a position vector, a velocity vector, and its prior best position memory vector. In the search space, each member of the population is shifted by three vectors called inertia (first term), memory (second term), and collaboration (third term) as (11) - (13) [24].

$$
\begin{gathered}
V_{i}^{k+1}=\omega V_{i}^{k}+c_{1} r_{1}\left(X_{\text {Pbest }_{i}^{k}}-X_{i}^{k}\right)+c_{2} r_{2}\left(X_{\text {Gbest }_{i}^{k}}-X_{i}^{k}\right) \\
X_{i}^{k+1}=X_{i}^{k}+V_{i}^{k+1}
\end{gathered}
$$

where $\omega \geq 0$ is defined as the inertia weight factor

$$
\omega=\omega_{\max }-\frac{w_{\max }-\omega_{\min }}{\text { iter }_{\max }} \times \text { iter }
$$

\footnotetext{
Where:

$K \quad$ number of iterations,

$x_{\text {pbest }} \quad$ local best of particle position,

$x_{\text {Gbest }} \quad$ global best of particle position,

$v_{i} \quad$ velocity vector of the $\mathrm{i}^{\text {th }}$ particle,

$c_{1}, c_{2} \quad$ positive numbers represent cognitive and social components,

$r_{1}, r_{2}$ uniform distribution numbers in range [0,1],

iter number of current iterations,

itermax maximum number of iterations, and

$\omega_{\max }, \omega_{\min }$ initial and final weights
}

Particles move in a multi-dimensional search space in a PSO algorithm, and each particle adjusts its position to its own experience (specific allocation), as well as to other adjacent particles (global allocation).

\section{PROCEDURE OF PROBLEM SOLVING}

The problem is solved for the base case (without PV) and then the proposed algorithm is applied to determine the optimal location and size of the PV-CSs.

The procedure for solving the problem can be summarized as:

Step 1: Enter input data: line data, bus data, and PSO initial population (array) of particles with random positions and velocities on dimensions in the solution space. Set the iteration counter $\mathrm{k}=0$.

Step 2: Run the power-flow program, for the base case, to determine the bus voltage profile, branches current, and network power losses.

Step 3: Run PSO program to compute the CSs sizes and location according to iterative steps.

Step 4: In each step, a comparison between the new power loss and the base case loss. If the difference is less or equal to the tolerance error. Then stop and record the results. Otherwise, go to step 3 .

\section{CASE STUDY}

The proposed algorithm is applied to IEEE 33 bus test system to obtain the optimum location of EV-PV-CSs which minimizes the network losses using PSO technique. The proposed algorithm is implemented using a computer program built in Matlab environment. The test system can be described as a 3-phase radial distribution bus system with $12.66 \mathrm{kV}$, having 33-buses, 3 lateral, 37 branches as shown by Fig. 1.

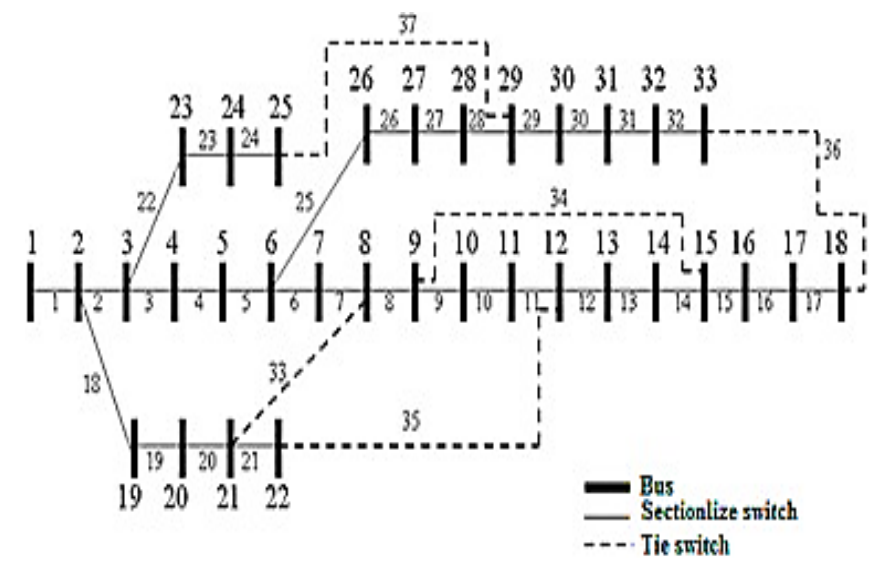

Fig.1: Schematic diagram of IEEE 33 bus radial distribution system [25]

\section{SIMULATION RESULTS}

The algorithm is applied to the aforementioned test system for minimizing power losses. The optimal sizes of PV-CSs are $1.75,1.85$, and $1.5 \mathrm{MW}$ and they are connected to buses 6,26 , and 27 respectively.

\section{A. Impact of $E V-P V$ size}

In this section, the effect of PV size is analyzed to clarify its impact on the feeder power loss. The computer program is 
performed for this case study for different PV sizes (70, 140, 210, 350, and $700 \mathrm{~m}^{2}$ ) and the results are expressed in Table 1 and Fig. 2. Table 1 explains the effect of PV size on real power loss. Whereas, Fig. 2 shows the voltage profile for these sizes. The voltage profile of 33-bus for different PV size is shown in Appendix A (Table A1).

TABLE1:

IMPACT OF PV SIZE ON REAL POWER LOSS REDUCTION AND SYSTEM VOLTAGE

\begin{tabular}{|c|c|c|c|}
\hline PV size & $\begin{array}{c}\text { Real power loss } \\
(\mathbf{k W})\end{array}$ & $\begin{array}{c}\text { Max. voltage } \\
\text { (p.u.) }\end{array}$ & $\begin{array}{c}\text { Min. voltage } \\
\text { (p.u.) }\end{array}$ \\
\hline Base case & 202.67 & 1.000 & 0.905 \\
\hline $70 \mathrm{~m}^{2}$ & 182.871 & 1.025 & 0.981 \\
\hline $140 \mathrm{~m}^{2}$ & 178.361 & 1.024 & 0.980 \\
\hline $210 \mathrm{~m}^{2}$ & 160.475 & 1.020 & 0.975 \\
\hline $350 \mathrm{~m}^{2}$ & 129.969 & 1.010 & 0.966 \\
\hline $700 \mathrm{~m}^{2}$ & 107.7485 & 1.000 & 0.948 \\
\hline
\end{tabular}

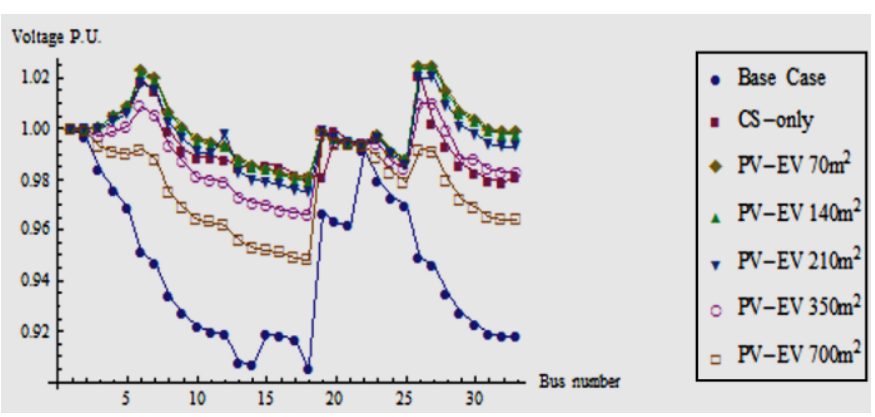

Fig.2: Voltage profile of 33 bus system for different PV sizes

It can be observed that the greater the area of the PV, the lower the values of power loss. On the other hand, increasing the PV size leads to a more decrease in the voltage profile. In this case, it is important to use reactive power compensation to decrease the impact on the system voltage profile. Unfortunately, these devices badly affect system power loss. An operational tradeoff is required to calculate the optimal PV size.

\section{B. Impact of solar radiation}

The Egyptian government has allowed the importation of electric vehicles and has already started to set up charging stations for these vehicles, and within the next five years, the government will begin to rely on PV to feed these stations. So, this section will clarify the effect of different solar radiation values on the feeder power loss based on Egypt's geographic location. Three values of solar radiation represent minimum, average, and maximum annual solar radiations values in Egypt $\left(3.84, \mathrm{kWh} / \mathrm{m}^{2}\right),\left(5.5 \mathrm{kWh} / \mathrm{m}^{2}\right)$ and $\left(8.1 \mathrm{kWh} / \mathrm{m}^{2}\right)$ are used to study the impact of solar radiation on both system power losses and voltage profiles at different buses. Table 2 shows the impact of solar radiation on the real power loss effect for different solar radiation values, whereas Fig. 3 depicts the voltage profile for these values. The voltage profile of 33-bus for different solar radiation is shown in Appendix A (Table A2).
TABLE 2:

IMPACT OF SOLAR RADIATION ON REAL POWER LOSS AND SYSTEM VOLTAGE

\begin{tabular}{c||c||c||c}
$\begin{array}{c}\text { Solar } \\
\text { radiation }\end{array}$ & $\begin{array}{c}\text { Real power } \\
\text { loss (kW) }\end{array}$ & $\begin{array}{c}\text { Max. voltage } \\
\text { (p.u.) }\end{array}$ & $\begin{array}{c}\text { Min. voltage } \\
\text { (p.u.) }\end{array}$ \\
\hline Base case & 202.67 & 1.000 & 0.905 \\
\hline $\mathbf{3 . 8 4} \mathbf{~ k W h} / \mathbf{m}^{\mathbf{2}}$ & 145.253 & 1.015 & 0.971 \\
\hline $\mathbf{5 . 5} \mathbf{~ k W h} / \mathbf{m}^{2}$ & 129.907 & 1.010 & 0.966 \\
\hline $\mathbf{8 . 1} \mathbf{~ k W h} / \mathbf{m}^{2}$ & 113.878 & 1.002 & 0.958
\end{tabular}

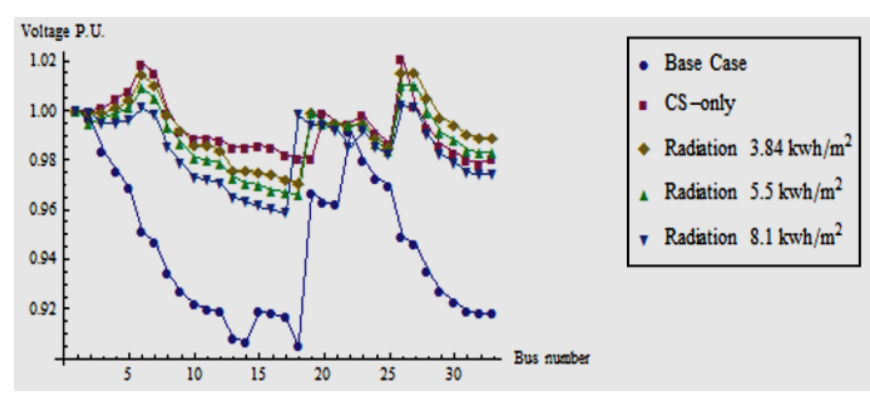

Fig.3: Voltage profile of 33 bus system for different solar radiation values

The simulation proves that, by increasing the solar radiation, the power loss reduction is increased, and the voltage profile becomes worse.

\section{Impact of solar cell type}

Solar cell type represents a major factor that affects the solar cell efficiency. Solar cell efficiency relates to the sunlight energy part that can be transformed into electricity through the solar cell. It has a very significant effect on PV output power. Most of the silicon-based solar cells on the market are consist of crystalline silicon including monocrystalline and polycrystalline. Another commercial type of solar cell is the thin-film solar cell. The thin-film solar cell sector accounted for about $4.5 \%$ of all cells on the market in 2017 [26]. This section discusses the impact of PV efficiency on feeder power loss. Table 3 shows the impact of different PV types with different efficiencies $12,16.9,22.5 \%$ for thin film, Polycrystalline, and Monocrystalline silicon respectively [27].

TABLE 3:

IMPACT OF PV EFFICIENCY ON REAL POWER LOSS AND SYSTEM VOLTAGE

\begin{tabular}{c||c||c||c} 
Solar cell type & $\begin{array}{c}\text { Real power } \\
\text { loss (kW) }\end{array}$ & $\begin{array}{c}\text { Max. voltage } \\
\text { (p.u.) }\end{array}$ & $\begin{array}{c}\text { Min. voltage } \\
\text { (p.u.) }\end{array}$ \\
\hline Base case & 202.67 & 1.000 & 0.905 \\
\hline $\begin{array}{c}\text { Thin Film Type } \\
\boldsymbol{\eta}=\mathbf{1 2 \%}\end{array}$ & 155.1284 & 1.018 & 0.974 \\
\hline $\begin{array}{c}\text { Polycrystalline } \\
\text { Silicon Type } \\
\boldsymbol{\eta}=\mathbf{1 6 . 9 \%}\end{array}$ & 142.1212 & 1.014 & 0.970 \\
\hline $\begin{array}{c}\text { Monocrystalline } \\
\text { Silicon Type } \\
\boldsymbol{\eta}=\mathbf{2 2 . 5 \%}\end{array}$ & 123.5548 & 1.010 & 0.966 \\
\hline
\end{tabular}

As the PV efficiency increases, the power loss reduction is increased, and the voltage profile becomes worse. Figure 4 illustrates the voltage profile for these cases whereas the full simulation results are shown in Appendix A (Table A3). 


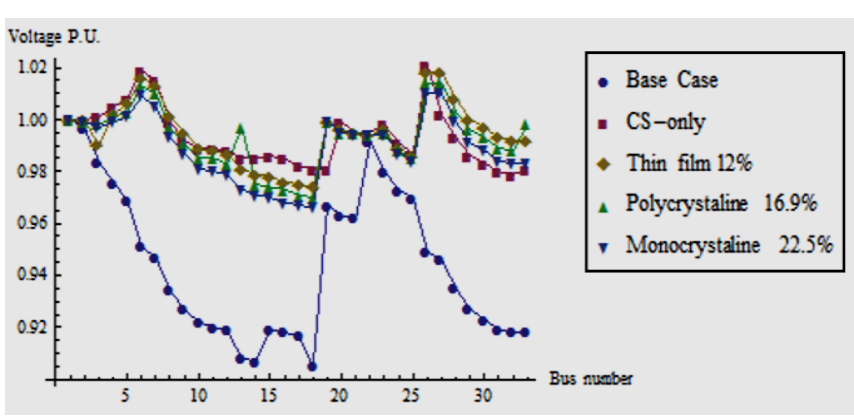

Fig. 4: Voltage profile of 33 bus system for different PV types

\section{CONCLUSION}

This paper presented a proposed method for optimal location of combined EV-PV charging stations in a distribution network. The main objective of the proposed method was to determine the optimal allocation of CSs for loss reduction subjected to system constraints. The problem is formulated as a problem of optimization with an objective function that cannot be differentiated. The proposed method depended on PSO for solving the optimization problem. The algorithm was performed in Matlab/Simulink environment and applied to an IEEE 33-bus radial distribution system with and without integrating the PV system and the results were compared. The obtained results proved that the EV-PV charging station was a suitable solution for reducing the feeder losses compared to those stations without PV. The effect of PV size, type, efficiency, and the charging station location were studied. By increasing the PV size, solar radiation, PV efficiency, the power loss was decreased, and the voltage profile became worse. Reactive power compensators are required to mitigate the impact of the EV-PV charging stations on the system voltage. These devices are badly affecting the system power loss and a tradeoff is required to calculate the optimal PV size.

\section{REFERENCES}

[1] M. S. Whittingham, "History, evolution, and future status of energy storage," Proceedings of the IEEE, vol. 100, pp. 1518-1534, 2012.

[2] P. A. Guerrero, L. Jingshan, S. Biller, X. Guoxian, " Hybrid/electric vehicle battery manufacturing: the state-of-the-art," In Proceedings of IEEE conference on automation science and engineering, 281-286, 2010.

[3] M. Chris and M. Abul Masrur, "Hybrid Electric Vehicles: Principles and Applications with Practical Perspectives," 2nd Edition, John Wiley \& Sons, Inc., 2017

[4] İ. Şengör et al. "Optimal Energy Management of EV Parking Lots Under Peak Load Reduction Based DR Programs Considering Uncertainty," IEEE Transactions on Sustainable Energy, vol. 10, pp. 1034-1043, 2019.

[5] S. Deb, K. Tammi, K. Kalita and P. Mahanta, "Impact of electric vehicle charging station load on distribution network", Energies 2018, 11, 178; doi:10.3390/en11010178

[6] Matteo Muratori, "Impact of uncoordinated plug-in electric vehicle charging on residential power demand", Nature energy, Vol. 3, March 2018, pp. 193-201.

[7] P. P. Barker and J. M. Bing, "Advances in solar photovoltaic technology: an applications perspective," Proceedings of power engineering society general meeting, vol.2, pp. 1955-1960, 2005.

[8] Feldman, et al., "Photovoltaic (PV) pricing trends: historical, recent, and near-term projections," National Renewable Energy Laboratory (NREL), Technical Report submitted to U.S. Department of Energy, USA, Nov. 2012
[9] K. Branker, M. J. M. Pathak, J. M. Pearce, "A review of solar photovoltaic levelized cost of electricity," Renewable and Sustainable Energy Reviews, vol. 15, pp. 4470-4482, 2011.

[10] P. Kadar and A. Varga, "Photovoltaic EV charge station," Proceedings of IEEE 11th international symposium on applied machine intelligence and informatics (SAMI), pp. 57-60, 2013.

[11] Y. Choe, J. S. Kim, B. K. Lee, C. Y. Won, T. W. Lee, " A Bi-directional battery charger for electric vehicles using photovoltaic PCS systems," In 2010 IEEE Vehicle Power and Propulsion Conference, pp. 1-6, 2010.

[12] J. Traube, et al. "Mitigation of solar irradiance intermittency in photovoltaic power systems with integrated electric-vehicle charging functionality," IEEE Transactions on Power Electronics, vol. 28, pp. 3058- 3067, 2012.

[13] Hamilton, G. Gamboa, J. Elmes, R. Kerley, A. Arias, M. Pepper, I. Batarseh, " System architecture of a modular direct-DC PV charging station for plug-in electric vehicles," In IECON 2010-36th Annual Conference on IEEE Industrial Electronics Society, pp.2516-2520, 2010.

[14] C. Mouli, P. Bauer, M. Zeman, " Comparison of system architecture and converter topology for a solar-powered electric vehicle charging station," In 2015 9th International Conference on Power Electronics and ECCE Asia (ICPE-ECCE Asia), pp. 1908-1915, 2015.

[15] P. Goli and W. Shireen, "PV powered smart charging station for PHEVs," Renewable Energy, vol. 66, pp. 280-287, 2014.

[16] Gamboa, C. Hamilton, R. Kerley, S. Elmes, A. Arias, J. Shen, I. Batarseh, "Control strategy of a multi-port, grid-connected, direct-DC PV charging station for plug-in electric vehicles," In 2010 IEEE Energy Conversion Congress and Exposition, pp. 1173-1177, 2010.

[17] F. Fattori, N. Anglani, G. Muliere, "Combining photovoltaic energy with electric vehicles, smart charging, and vehicle-to-grid," Solar Energy, vol. 110, pp. 438-451, 2014.

[18] O. Hafez and K. Bhattacharya, "Optimal design of electric vehicle charging stations considering various energy resources," Renewable Energy, vol. 107, pp. 576-589, 2017.

[19] G. C. Mouli, P. Bauer, M. Zeman, M. "System design for a solar-powered electric vehicle charging station for workplaces," Applied Energy, vol. 168, pp. 434-443, 2016

[20] W. Khan, F. Ahmad, M. S. Alam, "Fast EV charging station integration with grid ensuring optimal and quality power exchange," Engineering Science and Technology, vol. 22(1), pp. 143-152, 2019.

[21] A. Domínguez-Navarro, et al., "Design of an electric vehicle fast-charging station with integration of renewable energy and storage systems," International Journal of Electrical Power \& Energy Systems, vol. 105, pp. 46-58, 2019.

[22] M. Rupa and S. Ganesh, "Power flow analysis for radial distribution system using backward/forward sweep method. International Journal of Electrical, Computer, Electronics and Communication Engineering, 8(10), 1540-1544, 2014.

[23] F. Benhamida, Y. Salhi, S. Souag, A. Graa, Y. Ramdani, A. Bendaoud, "A PSO algorithm for economic scheduling of power system incorporating wind-based generation," In 2013 5th International Conference on Modeling, Simulation and Applied Optimization (ICMSAO), 1-6, 2013.

[24] Y. Zhang, S. Wang, G. Ji, "A comprehensive survey on particle swarm optimization algorithm and its applications". Mathematical Problems in Engineering, vol. 2015, 2015.

[25] R. Rajaram, K. S. Kumar, N. Rajasekar, "Power system reconfiguration in a radial distribution network for reducing losses and to improve voltage profile using modified plant growth simulation algorithm with Distributed Generation (DG)," Energy Reports, vol. 1, pp. 116-122. 2015.

[26] "Photovoltaics Report", Prepared by Fraunhofer Institute for Solar Energy Systems, ISE with support of PSE GmbH Freiburg, Nov. 2019, available at:

https://www.ise.fraunhofer.de/content/dam/ise/de/documents/publications/stu dies/Photovoltaics-Report.pdf

[27] M. A. Green, et al. " Solar cell efficiency tables (Version 55)", Progress in Photovoltaics, Volume: 28; Issue: 1; Jan. 2020.

\section{Title in Arabic:}

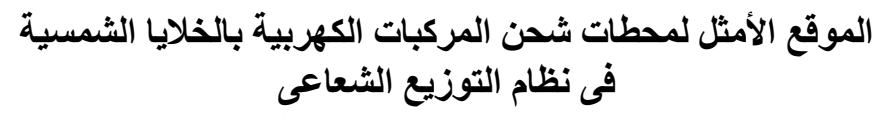

Abstract in Arabic:

ان الاتجاه المتزايد لاستخام السيارات الكهربية سيؤثر بثكل كبير على شبكات 


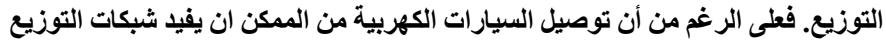

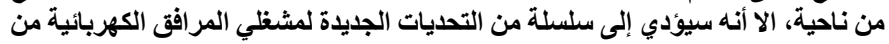

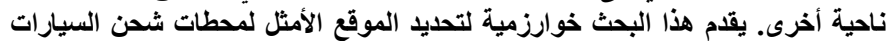

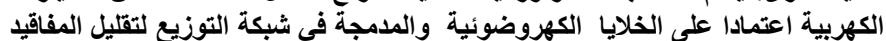
بالنظام وتعتمد الخوارزمية المقترحة على تقنية أمثلة جزئيات الأسراب لحئ لحل مشكلة كما تم تطبيقها على نظام Matlab / Simulink التحسين. وقد تم تنفيذ الطريقة في بيئة
اختبار قياسى للتوزيع الشعاعي لـ 33 نقطة مع وبدون دمج نظام الخلايا الشمسية وتم

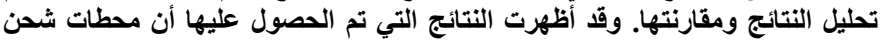

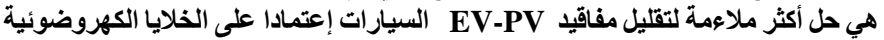

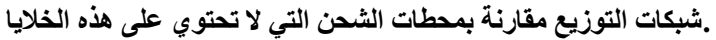

\section{Appendix A: Voltage profile of 33-bus for different variables}

TABLE A1:

VOLTAGE PROFILE OF 33-BUS FOR DIFFERENT PV SIZE

\begin{tabular}{|c|c|c|c|c|c|c|}
\hline \multirow{2}{*}{ Bus. No. } & \multirow{2}{*}{ Base case } & \multicolumn{5}{|c|}{ PV size } \\
\hline & & $70 \mathrm{~m}^{2}$ & $140 \mathrm{~m}^{2}$ & $210 \mathrm{~m}^{2}$ & $350 \mathrm{~m}^{2}$ & $700 \mathrm{~m}^{2}$ \\
\hline 1 & 1.000 & 1.000 & 1.000 & 1.000 & 1.000 & 1.000 \\
\hline 2 & 0.997 & 1.000 & 1.000 & 1.000 & 0.999 & 0.999 \\
\hline 3 & 0.984 & 1.001 & 1.001 & 1.000 & 0.997 & 0.993 \\
\hline 4 & 0.976 & 1.005 & 1.005 & 1.003 & 0.999 & 0.991 \\
\hline 5 & 0.969 & 1.009 & 1.009 & 1.006 & 1.001 & 0.990 \\
\hline 6 & 0.951 & 1.023 & 1.022 & 1.018 & 1.009 & 0.992 \\
\hline 7 & 0.947 & 1.020 & 1.019 & 1.015 & 1.005 & 0.988 \\
\hline 8 & 0.934 & 1.007 & 1.006 & 1.002 & 0.993 & 0.975 \\
\hline 9 & 0.927 & 1.001 & 1.000 & 0.996 & 0.987 & 0.969 \\
\hline 10 & 0.922 & 0.996 & 0.995 & 0.991 & 0.981 & 0.964 \\
\hline 11 & 0.920 & 0.995 & 0.994 & 0.990 & 0.980 & 0.963 \\
\hline 12 & 0.919 & 0.993 & 0.993 & 0.998 & 0.979 & 0.962 \\
\hline 13 & 0.908 & 0.988 & 0.987 & 0.983 & 0.973 & 0.965 \\
\hline 14 & 0.907 & 0.986 & 0.985 & 0.980 & 0.971 & 0.953 \\
\hline 15 & 0.919 & 0.984 & 0.984 & 0.979 & 0.970 & 0.952 \\
\hline 16 & 0.918 & 0.983 & 0.982 & 0.978 & 0.968 & 0.951 \\
\hline 17 & 0.917 & 0.981 & 0.980 & 0.976 & 0.967 & 0.949 \\
\hline 18 & 0.905 & 0.981 & 0.980 & 0.975 & 0.966 & 0.948 \\
\hline 19 & 0.967 & 0.999 & 0.999 & 0.999 & 0.999 & 0.998 \\
\hline 20 & 0.963 & 0.996 & 0.996 & 0.996 & 0.995 & 0.994 \\
\hline 21 & 0.962 & 0.995 & 0.995 & 0.995 & 0.994 & 0.994 \\
\hline 22 & 0.992 & 0.994 & 0.994 & 0.994 & 0.994 & 0.993 \\
\hline 23 & 0.980 & 0.998 & 0.997 & 0.996 & 0.994 & 0.989 \\
\hline 24 & 0.973 & 0.991 & 0.991 & 0.990 & 0.987 & 0.983 \\
\hline 25 & 0.970 & 0.988 & 0.988 & 0.986 & 0.984 & 0.979 \\
\hline 26 & 0.949 & 1.025 & 1.024 & 1.020 & 1.010 & 0.992 \\
\hline 27 & 0.946 & 1.025 & 1.024 & 1.020 & 1.010 & 0.991 \\
\hline 28 & 0.935 & 1.015 & 1.013 & 1.009 & 0.999 & 0.980 \\
\hline 29 & 0.927 & 1.007 & 1.006 & 1.001 & 0.988 & 0.972 \\
\hline 30 & 0.923 & 1.004 & 1.003 & 0.998 & 0.988 & 0.969 \\
\hline 31 & 0.919 & 1.000 & 0.999 & 0.994 & 0.984 & 0.965 \\
\hline 32 & 0.918 & 0.999 & 0.998 & 0.993 & 0.983 & 0.964 \\
\hline 33 & 0.918 & 0.999 & 0.998 & 0.993 & 0.983 & 0.964 \\
\hline
\end{tabular}

TABLE A2:

VOLTAGE PROFILE OF 33-BUS FOR DIFFERENT SOLAR RADIATION

\begin{tabular}{|c|c|c|c|c|}
\hline \multirow{2}{*}{$\begin{array}{c}\text { Bus. } \\
\text { No. }\end{array}$} & \multirow{2}{*}{ Base case } & \multicolumn{3}{|c|}{ Solar radiation } \\
\hline & & $3.84 \mathrm{kWh} / \mathrm{m}^{2}$ & $5.5 \mathrm{kWh} / \mathrm{m}^{2}$ & $8.1 \mathrm{kWh} / \mathrm{m}^{2}$ \\
\hline 1 & 1.000 & 1.000 & 1.000 & 1.000 \\
\hline 2 & 0.997 & 0.999 & 0.999 & 0.999 \\
\hline 3 & 0.984 & 0.999 & 0.997 & 0.995 \\
\hline 4 & 0.976 & 1.001 & 0.999 & 0.995 \\
\hline 5 & 0.969 & 1.004 & 1.001 & 0.996 \\
\hline 6 & 0.951 & 1.014 & 1.009 & 1.001 \\
\hline 7 & 0.947 & 1.010 & 1.005 & 0.998 \\
\hline 8 & 0.934 & 0.998 & 0.993 & 0.985 \\
\hline 9 & 0.927 & 0.992 & 0.987 & 0.979 \\
\hline 10 & 0.922 & 0.986 & 0.981 & 0.973 \\
\hline 11 & 0.920 & 0.986 & 0.980 & 0.972 \\
\hline
\end{tabular}




\begin{tabular}{|c|c|c|c|c|}
\hline 12 & 0.919 & 0.984 & 0.979 & 0.971 \\
\hline 13 & 0.908 & 0.976 & 0.973 & 0.965 \\
\hline 14 & 0.907 & 0.976 & 0.971 & 0.963 \\
\hline 15 & 0.919 & 0.975 & 0.970 & 0.961 \\
\hline 16 & 0.918 & 0.974 & 0.968 & 0.960 \\
\hline 17 & 0.917 & 0.972 & 0.967 & 0.958 \\
\hline 18 & 0.905 & 0.971 & 0.966 & 0.998 \\
\hline 19 & 0.967 & 0.999 & 0.999 & 0.994 \\
\hline 20 & 0.963 & 0.995 & 0.995 & 0.994 \\
\hline 21 & 0.962 & 0.995 & 0.994 & 0.992 \\
\hline 22 & 0.992 & 0.994 & 0.994 & 0.985 \\
\hline 23 & 0.980 & 0.995 & 0.994 & 0.992 \\
\hline 24 & 0.973 & 0.989 & 0.987 & 0.985 \\
\hline 25 & 0.970 & 0.985 & 0.984 & 0.982 \\
\hline 26 & 0.949 & 1.015 & 1.010 & 1.002 \\
\hline 27 & 0.946 & 1.015 & 1.010 & 1.001 \\
\hline 28 & 0.935 & 1.005 & 0.999 & 0.990 \\
\hline 29 & 0.927 & 0.997 & 0.991 & 0.982 \\
\hline 30 & 0.923 & 0.994 & 0.988 & 0.979 \\
\hline 31 & 0.919 & 0.990 & 0.984 & 0.975 \\
\hline 32 & 0.918 & 0.989 & 0.983 & 0.974 \\
\hline 33 & 0.918 & 0.989 & 0.983 & 0.974 \\
\hline
\end{tabular}

TABLE A3:

VOLTAGE PROFILE OF 33-BUS FOR DIFFERENT PV TYPES

\begin{tabular}{|c|c|c|c|c|}
\hline Bus. No. & Base case & $\begin{array}{c}\text { Thin Film Type } \\
\eta=12 \%\end{array}$ & $\begin{array}{c}\text { Polycrystalline Silicon } \\
\text { Type } \\
\eta=16.9 \%\end{array}$ & $\begin{array}{c}\text { Monocrystalline Silicon } \\
\text { Type } \\
\eta=\mathbf{2 2 . 5} \%\end{array}$ \\
\hline 1 & 1.000 & 1.000 & 1.000 & 1.000 \\
\hline 2 & 0.997 & 1.000 & 0.999 & 0.999 \\
\hline 3 & 0.984 & 0.999 & 0.998 & 0.997 \\
\hline 4 & 0.976 & 1.002 & 1.001 & 0.999 \\
\hline 5 & 0.969 & 1.006 & 1.003 & 1.001 \\
\hline 6 & 0.951 & 1.016 & 1.013 & 1.009 \\
\hline 7 & 0.947 & 1.013 & 1.010 & 1.005 \\
\hline 8 & 0.934 & 1.001 & 0.997 & 0.993 \\
\hline 9 & 0.927 & 0.995 & 0.991 & 0.987 \\
\hline 10 & 0.922 & 0.989 & 0.985 & 0.981 \\
\hline 11 & 0.920 & 0.988 & 0.985 & 0.980 \\
\hline 12 & 0.919 & 0.987 & 0.983 & 0.979 \\
\hline 13 & 0.908 & 0.981 & 0.977 & 0.973 \\
\hline 14 & 0.907 & 0.979 & 0.975 & 0.971 \\
\hline 15 & 0.919 & 0.978 & 0.974 & 0.970 \\
\hline 16 & 0.918 & 0.976 & 0.973 & 0.968 \\
\hline 17 & 0.917 & 0.975 & 0.971 & 0.967 \\
\hline 18 & 0.905 & 0.974 & 0.970 & 0.966 \\
\hline 19 & 0.967 & 0.999 & 0.999 & 0.999 \\
\hline 20 & 0.963 & 0.996 & 0.995 & 0.995 \\
\hline 21 & 0.962 & 0.995 & 0.995 & 0.994 \\
\hline 22 & 0.992 & 0.994 & 0.994 & 0.994 \\
\hline 23 & 0.980 & 0.996 & 0.995 & 0.994 \\
\hline 24 & 0.973 & 0.989 & 0.988 & 0.987 \\
\hline 25 & 0.970 & 0.986 & 0.985 & 0.984 \\
\hline 26 & 0.949 & 1.018 & 1.014 & 1.010 \\
\hline 27 & 0.946 & 1.018 & 1.014 & 1.010 \\
\hline 28 & 0.935 & 1.008 & 1.003 & 0.999 \\
\hline 29 & 0.927 & 1.000 & 0.996 & 0.991 \\
\hline 30 & 0.923 & 0.997 & 0.993 & 0.988 \\
\hline 31 & 0.919 & 0.993 & 0.989 & 0.984 \\
\hline 32 & 0.918 & 0.992 & 0.988 & 0.983 \\
\hline 33 & 0.918 & 0.992 & 0.988 & 0.983 \\
\hline
\end{tabular}

